\title{
Phosphorus and nitrogen nutritional status of a northern Australian mangrove forest
}

\author{
Kevin G. Boto and John T. Wellington
}

Australian Institute of Marine Science, P.M.B. No. 3, Townsville, M.S.O., Queensland 4810, Australia

\begin{abstract}
Three sites along a 400-m transect within a tropical mangrove forest in northern Australia were monitored at monthly intervals for 12 mo to determine mangrove response to soil ammonium or phosphate enrichment. Growth response was monitored by measurement of interpetiolar stipule fall, a litter fall component which has been found to be highly correlated with new leaf appearance. Regression slopes for the cumulative stipule fall-time data for each site (2 replicate catchers per site) were used to estimate average stipule fall rates over the treatment year. These were compared with the rates obtained for the identical catcher pairs from a previous year when no treatment was applied. Similar between-year comparisons for 3 corresponding control sites, with no treatment either year, showed no significant changes in stipule fall rates ( $p>0.17$ in all cases). At the first treatment site, at low elevation within the intertidal zone, no significant response $(p=0.53)$ to $P$ enrichment was found. For a higher elevation site, $170 \mathrm{~m}$ from the nearest tidal channel edge, a significant $(\mathrm{p}=0.017)$ response to $\mathrm{P}$ enrichment was recorded, consistent with previous findings of chronically low soil extractable $P$ at the higher elevation sites compared to the lower elevation (edge) sites (5 vs. $14 \mu \mathrm{g} P$ $\mathrm{g}^{-1}$ ). A significant response $(\mathrm{p}=0.018)$ to soil ammonium enrichment was found at the third (edge, low elevation) site. As the average soil ammonium level at this site was slightly but significantly higher than for all other sites, it appears that nitrogen limitation is common throughout with phosphorus limitation also evident at the higher elevation areas. Foliar analyses showed that mature Rhizophora leaf nitrogen and phosphorus levels were highly significantly correlated with average soil ammonium. and extractable phosphorus respectively. Mature leaves are therefore likely to be useful indicators of mangrove forest nutritional status in remote area surveys. Newly formed leaves showed much higher $\mathrm{N}$ and $\mathrm{P}$ levels and the leaf parameters showed a complex set of correlations with other soil factors such as redox potential and salinity,
\end{abstract}

\section{INTRODUCTION}

Tropical mangrove forests in north Queensland (Australia) have been shown to be generally highly productive and capable of sustaining high rates of litter production (Bunt et al., 1979; Duke, 1981; Duke et al., 1981; Bunt, 1982). However, examination of litterfall data reveals that these forests, in many cases, are producing at well below maximum capacity. This is illustrated by the following considerations: at only 2 of the 60 sites monitored did litter yields approach a value of $20 \mathrm{Mg} \mathrm{ha}^{-1} \mathrm{y}^{-1}$ organic dry wt. The range at all other sites was between 6 and $11 \mathrm{Mg} \mathrm{ha}^{-1} \mathrm{y}^{-1}$. The upper limit of $20 \mathrm{Mg} \mathrm{ha}^{-1} \mathrm{y}^{-1}$ is very similar to the very high litter production rates reported for a mangrove forest in Thailand (Christensen, 1978) and for rain forests in Thailand (Kira et al., 1967) and Africa (Rodin and Basilevic, 1968). This level of production is prob- ably close to a maximum for tropical forests in general. It is clear that the north Queensland mangroves, while sustaining high productivity, are nevertheless growing under less than optimal conditions at most sites.

A preliminary study at one of these sites (Boto and Wellington, in press) has shown that the mangrove biomass (above ground) was significantly correlated with the following soil factors, averaged over a $14 \mathrm{mo}$ period: Extractable phosphorus $(r=0.85, \mathrm{p}<0.01)$, redox potential $(\mathrm{r}=0.89, \mathrm{p}<0.01)$ and salinity $(\mathrm{r}=$ $-0.79, p<0.05)$. These results indicated that phosphorus limitation, among other factors, may be a major control on mangrove growth. This hypothesis is consistent with the generally poor phosphorus status of many Australian soils (Beadle, 1953). In addition, while soil ammonium (the major component of inorganic $\mathrm{N}$ in the soils) did not correlate significantly with biomass ( $\mathrm{r}=$ $0.62, \mathrm{p}=0.10)$ the correlation coefficient was suspi- 
ciously high. Also, the soil ammonium levels (1 to 14 ppm) were similar to those found in saltmarsh systems that have been shown to be nitrogen limited (Buresh et al., 1980). Hence, a more detailed investigation of the possibility of nitrogen and phosphorus limitation was warranted.

This paper reports the results of a 12 -mo field study in which mangrove response to soil nitrogen and phosphorus enrichment was monitored. A novel method involving measurement of interpetiolar stipule fall rate was found to be successful for monitoring growth response. In addition, having estabilished the conditions under which nitrogen and/or phosphorus limitation could be expected, foliar $\mathrm{N}$ and $\mathrm{P}$ analyses were correlated with established soil conditions. These studies were carried out to determine the utility of mangrove foliar $N$ and $P$ levels as indicators of long term nutrient status for remote area surveys.

\section{STUDY AREA}

A detailed description of the study area at Hinchinbrook Island (Lat. $18^{\circ} 13^{\prime} \mathrm{S}$, Long. $146^{\circ} 11^{\prime} \mathrm{E}$ ) is given in previous publications (Bunt et al., 1979; Boto and Wellington, in press). It suffices here to recount briefly some relevant details of the study transect: The transect traverses a vegetational area between 2 tidal channels (Fig. 1). All mangrove species present are of

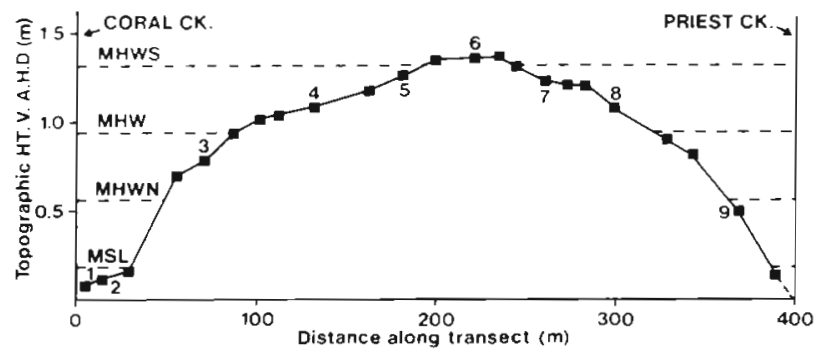

Fig. 1. Cross sectional diagram of the study transect, showing the variation in elevation with position and some tidal data for the area. All topographic elevations are in metres vs. A. H. D. (Australian High Datum). MHWS: mean high water spring; MHW: mean high water; MHWN: mean high water neap; MSL: mean sea level. Data were supplied by the Australian Government Survey Office

the Rhizophoracae family and consist of Rhizophora stylosa, $R$. apiculata, $R$. lamarckii, Bruguiera gymnorhiza and Ceriops tagal. Between Sites 1 and $5, R$. stylosa, $R$. apiculata, B. gymnorhiza and $R$. lamarckii, in that order of dominance, are present. C. tagal is in evidence between Sites 3 and 8 and is co-dominant with $R$. stylosa at the more elevated sites. At Sites 8 and $9, R$. stylosa and $R$. apiculata are co-dominant. Over the 8 sampling sites established in the previous study, average soil ammonium levels ( \pm standard deviation) varied between $4.6( \pm 2.2)$ and $7.3( \pm 2.6) \mu \mathrm{g} \mathrm{N} \mathrm{g}{ }^{-1}$ dry soil. Average soil extractable phosphorus values showed a much greater variation with position along the transect. At each edge site, the values were 14.2 $( \pm 3.8)$ and $20.1( \pm 4.0)$, while in the middle site the average value was $5.0( \pm 2.2) \mu \mathrm{g} \mathrm{g} \mathrm{g}^{-1}$. The probable major reason for the lower soil nutrient levels at the elevated sites is the much lesser degree of tidally influenced sediment exchange compared to the situation at the edge (low elevation) sites. Sediment-laden incoming tidal water encounters high resistance to flow due to the presence of the high vegetation density, particularly the massive prop root structures of the Rhizophora species (Wolanski et al., 1980). Hence the flow is greatly reduced, causing most of the sediment to be deposited at the lower elevation sites. This factor is especially important for phosphorus nutrition as it would be expected that sediment exchange represents a major source of $\mathrm{P}$ renewal to the vegetated areas. Canopy heights varied from ca. $15 \mathrm{~m}$ at the edges to ca. $3 \mathrm{~m}$ at the middle sites while above ground bionass, expressed as wood volume per unit land area, ranged from $0.83( \pm 0.15)$ to $0.11( \pm 0.10) \mathrm{m}^{3} 10 \mathrm{~m}^{-2}$.

\section{METHODS}

\section{$\mathbf{P}$ and $\mathbf{N}$ fertilization studies}

Three separate sites along the transect were chosen for soil enrichment experiments - edge sites at each end of the transect and one middle site. Soil treatments were carried out according to the following scheme: Edge site 1 - phosphate addition, Middle site - phosphate addition and Edge site 2 - ammonium addition. At each site, treatment was applied within a $12 \times 7 \mathrm{~m}$ marked area. Each treatment area and its corresponding control area ca. $20 \mathrm{~m}$ distant, was monitored by 2 litter catchers, each catcher being $2.0 \mathrm{~m}^{2}$ in area. Despite the variations in mangrove species distributions along the transect, each fertilized and control site was essentially dominated by Rhizophora stylosa. Minor contributions from other species were noted in the litter, for example, some $R$. apiculata and Bruguiera gymnorhiza was evident in the edge P sites, while some Ceriops tagal litter was consistently found in the middle $\mathrm{P}$ site. However, the contributions from species other than the ubiquitous $R$. stylosa were always minor and the possible effect of this minor variation was minimized by the fact that the species composition at treatment and corresponding control sites was very similar in all cases. For $\mathrm{P}$ fertilization, superphosphate fertilizer, at a rate of $100 \mathrm{~kg} \mathrm{Pha}^{-1}$, was applied as a solid and buried at $30 \mathrm{~cm}$ depth in the 
soil at a large number of positions within the borders of the area. For nitrogen enrichment, ammonium sulfate solution, at a rate of $100 \mathrm{~kg} \mathrm{~N}^{-1}$, was injected into the soil at $30 \mathrm{~cm}$ depth. All treatment were begun on July 25, 1979 and repeated 3 times at 3-mo intervals after that date

Litter collections from treatment and control sites were made at approximately monthly intervals beginning August 25, 1979 and continuing until September 2 , 1980. The litter was sorted into its various components, dried, and weighed. Of the components, only the stipule data are relevant here. For mangroves of the Rhizophoracae, the rate of interpetiolar stipule fall has been found to be highly correlated with the rate of new leaf appearance $(\mathrm{r}=0.93, \mathrm{p}<0.01)$, as shown by studies in which tagged leaf crowns were monitored for new leaf appearance and compared with stipule fall (Duke et al., in press). This method was considered to be the most logistically feasible and sensitive method for monitoring the mangrove response to soil enrichment.

Previous experience has shown that stipule fall rates vary widely between sites, probably depending on the catcher position in relation to canopy cover, types of species represented etc. However, the variation from year to year for any given catcher is not nearly as large. For these reasons, it was decided to compare the present (1979-80) data for a given pair of catchers, at a treatment or control site, with previously obtained (1977-78) data for the same catchers (Duke, 1981) when no treatments were applied.

For any given site, the cumulative stipule fall, calculated at the end of each collection period, was regressed on the cumulative time lapsed since the beginning of the experiment. Regression calculations were performed as described by Sokal and Rohlf (1969, pp. 430 to 432 ) for the case of replicate $Y$ values (i.e. cumulative stipule fall, 2 replicate catchers per site) for each $\mathrm{X}$ value (cumulative time). The slope of the linear regression was used as an estimate of the average stipule fall rate for that particular site and year. Comparison between years was made using a standard method for testing equality of regression slopes (Sokal and Rohlf, 1969, pp. 450 to 455 ), which computes an $F$ ratio for variations among/within regressions. The slopes, and hence the average rates, were considered to vary significantly if $F$ was greater than the value corresponding to $\mathrm{p}=0.05$, as determined from $\mathrm{F}$ distribution tables.

\section{Foliar analyses}

Leaf samples were collected at each of the 8 sites used for the previous studies and at each of the fertilized sites. Sampling at all sites was carried out at the end of the fertilization study. Rhizophora spp. only were sampled, although it was found unnecessary to distinguish species to any greater degree as virtually no differences between the foliar $N, P$ levels were found for the 3 Rhizophora spp. (ANOVA $-\mathrm{F}<1, \mathrm{n}=$ 20 for each species) at one site.

At each site, 60 mature (but not senescent) leaves and 60 newly formed leaves were collected from 2 to 3 trees in close proximity. To ensure sufficient sample for analyses, each batch of 60 leaves was made up into 20 samples, with 3 leaves per sample. Each sample was dried and ground to pass a $250 \mu \mathrm{m}$ sieve. After Kjeldahl digestion ( $0.3 \mathrm{~g}$ sample weight) using $\mathrm{Hg} \mathrm{O}$ catalyst, ammonia and phosphate determinations were carried out using standard colorimetric methods either manual or automated (Allen et al., 1974). Each digestion batch (40 samples) contained a sample of NBS

Table 1. Stipule fall $\left(\mathrm{g} \mathrm{m}^{-2}\right)$ for each catcher replicate (A and B) at Edge site 2, the N-treatment site. Cumulative totals up to the end of each time increment between collections. Cumulative time (d) lapsed since the beginning of the experiment shown for each interval. Slopes of stipule-time regressions for each year, and $F$ value for comparison of regression slopes

\begin{tabular}{|c|c|c|c|c|c|c|c|c|c|c|c|c|}
\hline Time lapsed $(\mathrm{d})$ & 25 & 72 & 108 & 129 & 163 & 180 & 212 & 247 & 284 & 312 & 339 & 365 \\
\hline Stipules - A & 5.6 & 20.6 & 26.0 & 27.6 & 36.7 & 48.8 & 62.7 & 86.0 & 114.6 & 123.6 & 138.8 & 143.7 \\
\hline Stipules - B & 5.6 & 22.5 & 26.6 & 28.4 & 31.4 & 37.4 & 44.6 & 72.2 & 91.2 & 99.6 & 116.1 & 120.9 \\
\hline \multicolumn{13}{|c|}{ Slope (rate) $=0.402 \mathrm{~g} \mathrm{~m}^{-2} \mathrm{~d}^{-1}$} \\
\hline \multicolumn{13}{|c|}{ 1979-80: Day $0=$ July 25, 1979. N-treatment } \\
\hline Time lapsed (d) & 31 & 62 & 90 & 119 & 137 & 182 & 213 & 246 & 279 & 307 & 334 & 405 \\
\hline Stipules - A & 2.8 & 7.3 & 15.7 & 38.0 & 56.0 & 73.6 & 92.6 & 112.4 & 130.4 & 144.0 & 150.5 & 170.5 \\
\hline Stipules - B & 3.9 & 9.5 & 17.5 & 36.4 & 45.3 & 61.5 & 87.7 & 106.7 & 123.4 & 141.4 & 144.5 & 159.5 \\
\hline \multicolumn{13}{|c|}{ Slope $=0.490 \mathrm{~g} \mathrm{~m}^{-2} \mathrm{~d}^{-1}$} \\
\hline
\end{tabular}


1571 orchard leaves for checking $\mathrm{N}$ and $\mathrm{P}$ recovery. Each sample was run in duplicate, with further replication if duplicates did not agree to within $\pm 0.05 \% \mathrm{~N}$ or $0.005 \% \mathrm{P}$ (absolute).

\section{RESULTS AND DISCUSSION}

\section{Fertilization studies}

As an example of the results obtained, full details of the stipule-time data for the ammonium fertilized site (1979-80) are shown in Table 1 along with the 1977-78 data (no treatment) for the same pair of catchers. The table shows the cumulative stipule fall at each collection interval and the cumulative time. Also shown are the regression slopes for each year and, finally, the F ratio for the between year comparison. For this site, the average rate of stipule fall for the year of $\mathrm{N}$ enrichment was significantly greater ( $p=0.018$ ) than for the year when no treatment was applied.

Summarised results for all of the sites, including control sites, are given in Table 2. For each site, the average stipule fall rates for the 2 different years are shown along with the F ratio for between year comparison. The results were:

(a) For all control sites, with no treatment in either year, no significant differences between the average rates for the 2 yr was found.

(b) At Edge site 1, where previous soil analyses showed an average soil extractable $P$ level of ca. 10-14 $\mu \mathrm{g} \mathrm{P} \mathrm{g}^{-1}$, no significant change between years was found, indicating a lack of response to soil $P$ enrichment, at least over the 1-yr period of study. This result also implies that the inevitable working of the soil during the fertilization process had no noticeable effect on growth.

(c) At the middle site, previously shown to be chronically low in soil $P$, relative to the Edge site $\left(5 \mu \mathrm{g} \mathrm{g}^{-1}\right.$ vs. $14 \mu \mathrm{g} \mathrm{g}^{-1}$ ), the average stipule fall rate for the treatment year ( $P$ enrichment) was significantly great- er than for the non-treatment year. This indicates that $P$ deficiency is a growth limiting factor at this site, although it is not necessarily the only limiting factor.

(d) The ammonium enriched site, as discussed above, also showed a significant response. As the average soil ammonium level at this site was previously found to be slightly, but significantly, greater than at all other sites, it seems reasonable to assume that all sites are similarly nitrogen limited. This also implies that the middle areas of the transect are subject to both phosphorus and nitrogen limitation, among other possible factors such as soil redox potential and salinity.

Comparison of this system with other mangrove forests is limited by the lack of comparable data for other systems. Hesse (1961), in his study of Sierra Leone mangrove soils, reports similar levels for soil ammonium to those found in the Hinchinbrook mangroves. However, the soil extractable $P$ levels (same extraction medium used) were of comparable magnitude to that found for the low elevation, higher soil $P$ sites reported here. Onuf et al. (1977) has reported that mangroves near Fort Pierce, Florida, exhibited increased luxuriance and higher foliar nitrogen levels at sites naturally enriched by guano. On the other hand, Clough and Attiwill (1980) did not observe any increased luxuriance in mangroves close to a sewage effluent site near Darwin, Australia, however, an increase in foliar $\mathrm{N}$ and $\mathrm{P}$ was noted, as compared to mangroves growing a further distance from the enriched areas. Potts (1979) has demonstrated the importance of nitrogen fixation by blue-green alga in the maintenance of an adequate nitrogen supply to mangroves growing in the oligotrophic Sinai region. The possibility of $P$ or Fe limitation influencing the algal production was noted in this area.

\section{Foliar $\mathbf{N}$ and $\mathbf{P}$}

The results of the fertilization study support some of the initial conclusions drawn from the previous study

Table 2. Comparison of stipule fall-time regression slopes (b, $\mathrm{g} \mathrm{m}^{-2} \mathrm{~d}^{-1}$ ) for 1977-78 (no treatment) and $1979-80$ (treatment) for all sites

\begin{tabular}{|c|c|c|c|c|}
\hline Site & Treatment (1979-80) & b $(1977-78)$ & b $(1979-80)$ & $F(1,20)$ \\
\hline Edge 1 & Phosphate & 0.272 & 0.284 & 0.37 (ns) \\
\hline Control & None & 0.409 & 0.391 & 0.40 (ns) \\
\hline Middle & Phosphate & 0.327 & 0.408 & $6.83^{\circ}(p=0.017)$ \\
\hline Control & None & 0.355 & 0.408 & 1.33 (ns) \\
\hline Edge 2 & Ammonium & 0.402 & 0.490 & $6.66^{\circ}(p=0.018)$ \\
\hline Control & None & 0.498 & 0.452 & $1.97^{+}$(ns) \\
\hline
\end{tabular}


of temporal and spatial variation of soil nutrients along the transect. However, these findings are strictly applicable to this locality only. To obtain information about the nutritional status of mangrove forests in more remote localities, a simple but reasonably precise indicator is required. Unlike the study site described here, where seasonal variation of soil nutrient status was not large and where only tidal influence is predominant, many of the coastal riverine systems do show large seasonal fluctuations in soil nutrients (Boto and Wellington, unpubl.). These large variations are presumed to be caused by flood deposition of nutrient rich silt during the summer (wet) season, with subsequent depletion by plant uptake and tidal leaching during the rest of the year. Regardless of the causes, it is obvious that infrequent soil sampling in these areas is not a feasible method of estimating average nutrient status.

It was therefore decided that foliar nitrogen and phosphorus may be better indicators of the average nutrient status of mangroves. The data available for the study area at Hinchinbrook provided an opportunity to test the relationships between leaf $N, P$, and soil factors. Information required to design a suitable sampling protocol for future surveys includes (a) the degree of correlation between foliar and soil N, P; (b) estimates of the population variance; and (c) the effect of leaf age.

Results obtained for $\mathrm{N}$ and $\mathrm{P}$ in mature Rhizophora leaves are shown in Table $3 a$ along with average values (over $14 \mathrm{mo}$ ) of some soil parameters obtained previously at the transect sites (Boto and Wellington, in press). Simple linear correlation analyses (Table $3 \mathrm{~b}$ ) revealed the following highly significant correlations: Leaf $\mathrm{N}$ and soil $\mathrm{NH}_{4}-\mathrm{N}(r=0.84, \mathrm{p}=0.009)$, leaf $\mathrm{P}$ and soil extractable $P(r=0.91, p=0.002)$. Also it can be seen that leaf $\mathrm{P}$ and soil $\mathrm{NH}_{4}-\mathrm{N}$ correlated to a lesser degree but nevertheless significantly $(\mathrm{r}=0.79, \mathrm{p}=$ 0.02). Neither leaf parameter correlated significantly with any other soil factor. Unfortunately, the range of soil $\mathrm{N}$ values over the transect was quite narrow and hence it is not known whether any correlations involving soil $\mathrm{N}$ would hold over the much greater range likely to occur between other locations. Despite this, it appears that mature leaf $\mathrm{N}$ and $\mathrm{P}$ levels are closely correlated with soil $\mathrm{N}$ and $\mathrm{P}$ respectively and hence should be useful indicators of nutrient status. The variance was quite high, but reasonably consistent for both parameters. It appears that reasonable estimates of population standard deviations would be in the order of $0.16 \% \mathrm{~N}$ and $0.014 \%$ P. Spain and Holt (1980) have reported similar variances for mature Rhizophora foliar N and P at a different location in north Queensland.

Results obtained for newly formed leaves (Table 4) were markedly different to those for mature leaves. Both $\mathrm{N}$ and $\mathrm{P}$ were significantly higher for new leaves and the variance in both parameters was much less. New leaf $\mathrm{N}$ did not correlate significantly with soil $\mathrm{N}$ $(\mathrm{r}=0.49, \mathrm{p}=0.22)$ but did show significant correlations with both soil redox potential $(\mathrm{r}=0.85, \mathrm{p}=$ $0.02)$, and salinity $(\mathrm{r}=-0.92, \mathrm{p}=0.001)$. New leaf $\mathrm{P}$

Table 3. (a) Nitrogen and phosphorus content of mature Rhizophora leaves from (untreated) transect sits. Means derived from 20 samples per site. Leaf N, P as \% dry wt. Average soil parameters (over 14 mo period) previously obtained for these sites also shown (Boto and Wellington, in press). Ex. N-extractable ammonium-nitrogen $\left(\mu \mathrm{g} \mathrm{g}^{-1}\right)$; Ex. P.-extractable P; Sal-soil water salinity $(\%) ; \mathrm{E}_{\mathrm{H}}$-redox potential $(\mathrm{mV})$. All values in parentheses are standard deviations

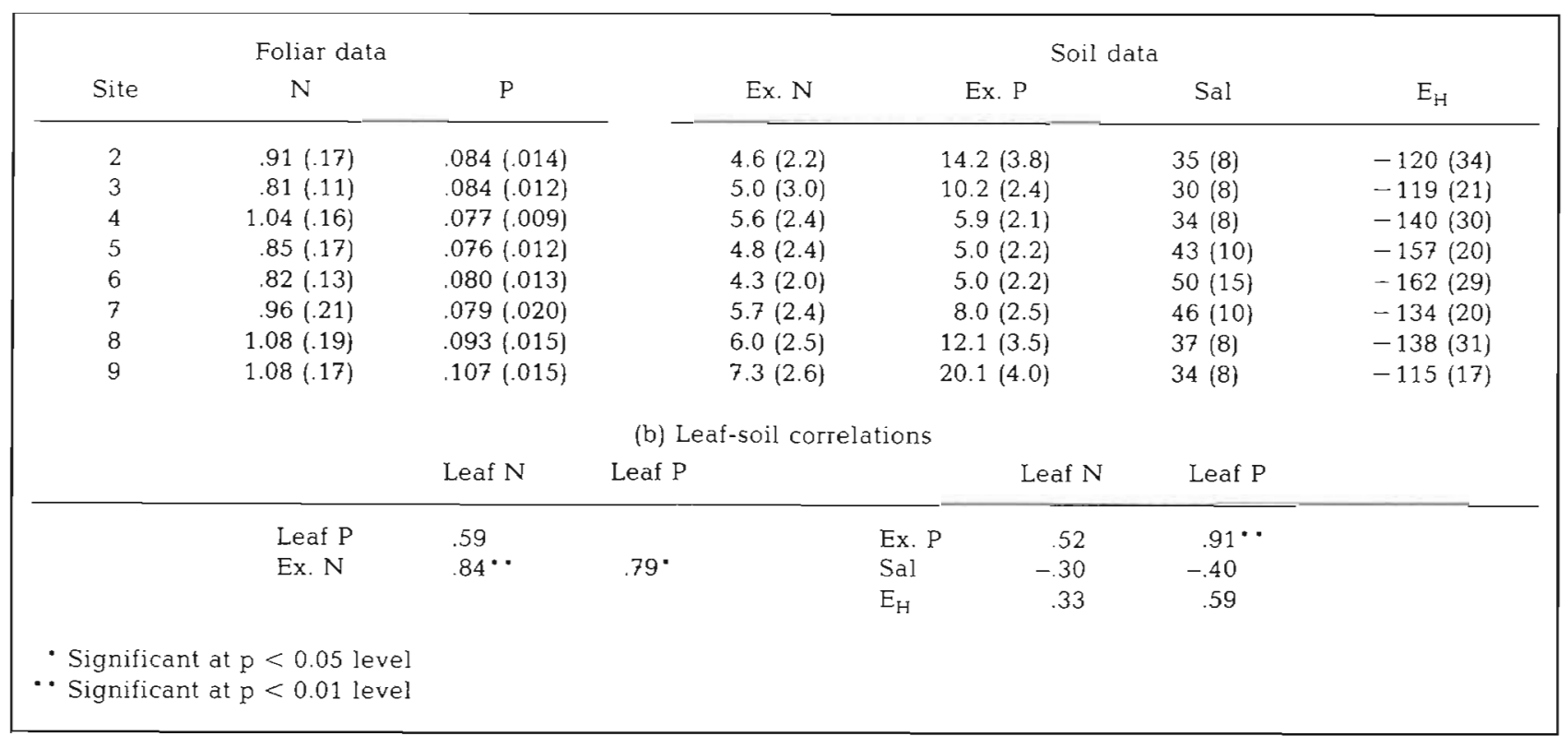


Table 4. Nitrogen and phosphorus content of newly formed Rhizophora leaves at catwalk sites (untreated). Results obtained for the new foliage at fertilized sites also shown. Position of data for fertilized sites indicates proximity to transect sites. For each mean value shown (standard deviation in parentheses) sample size $=20$. Leaf parameters expressed as $\%$ dry wt. P or $\mathrm{N}$ signifies the treatment applied

\begin{tabular}{|c|c|c|c|c|c|c|}
\hline \multicolumn{3}{|c|}{ Untreated catwalk sites } & \multicolumn{4}{|c|}{ Fertilized sites } \\
\hline Site & Leaf $N$ & Leaf $\mathrm{P}$ & Site & Leaf $\mathrm{N}$ & Leaf $\mathrm{P}$ & Treatment \\
\hline 2 & $1.20(.05)$ & $.106(.008)$ & & & & \\
\hline & & & Edge 1 & $1.43(.08)$ & $.102(.004)$ & $P$ \\
\hline 3 & $1.17(.06)$ & $.101(.004)$ & & & & \\
\hline 4 & $1.14(.07)$ & $.094(.006)$ & & & & \\
\hline 5 & $1.09(.06)$ & $.089(.004)$ & Middle & $1.06(.06)$ & $.095(.003)$ & $\mathrm{p}$ \\
\hline 6 & $.95(.05)$ & $.088(.006)$ & & & & \\
\hline 7 & $1.05(.04)$ & $.094(.004)$ & & & & \\
\hline 8 & $1.17(.05)$ & $.113(.005)$ & & & & \\
\hline 9 & $1.20(.06)$ & $.113(.009)$ & Edge 2 & $1.35(.05)$ & $.122(.005)$ & $N$ \\
\hline
\end{tabular}

Correlated significantly with soil $\mathrm{P}(\mathrm{r}=0.90, \mathrm{p}=0.002)$ and also with redox potential ( $r=0.75, p=0.03$ ). In addition leaf $N$ and leaf $P$ showed a significant intercorrelation $(\mathrm{r}=0.80, \mathrm{p}=0.02)$.

The results obtained for new leaves at fertilized sites were also of interest (Table 4). While mature leaves showed no significant differences when compared with the nearest untreated site, similar comparisons for new leaves gave the following results (using $t$ - test comparisons):

(a) For Edge site 1 ( $P$ fertilized), leaf $N$ increased highly significantly $(\mathrm{p}<0.001)$ while leaf $\mathrm{P}$ showed no significant change.

(b) At the Middle site (P fertilized), leaf $N$ showed no significant change while leaf $P$ increased highly significantly ( $\mathrm{p}<0.001)$.

(c) For Edge site 2 ( $\mathrm{N}$ fertilized), leaf $\mathrm{N}$ and $\mathrm{P}$ both showed highly significant increases ( $p<0.001$ for both).

These results, and the results for new leaves at untreated sites, indicate that new leaf $\mathrm{N}$ and $\mathrm{P}$ content is influenced or controlled by a complex set of factors. Much more experimental data would be required to establish cause and effect relationships, however it seems reasonable to suggest that mature leaves are better indicators of soil nutrient factors only. The observed lack of increase in mature leaf $N, P$ at fertilized sites is probably because these leaves, being greater than one year old, were less influenced by the change in soil conditions over the 1-yI experiment.

\section{CONCLUSIONS}

The significant growth response following ammonium enrichment at the edge site and the response to phosphate enrichment at the middle site imply that the mangrove growth in this locality is generally nitrogen limited with phosphorus limitation also a factor at the more elevated areas. Previous studies have indicated that these are probably not the only controls and it seems highly likely that complex interactions between soil nutrient status, salinity and redox potential are involved in the control of mangrove growth. For example, the effect of soil anaerobiosis in limiting nitrogen uptake, as suggested for saltmarsh systems (Mendelssohn, 1979; Lindhurst and Seneca, 1981), may also be important here, although a considerable amount of further data would be required to demonstrate such effects.

Similarly, the $\mathrm{N}$ and $\mathrm{P}$ content of newly formed Rhizophora leaves appear to be influenced by a number of soil factors. Mature leaves, however, appear to reflect only the long term soil nutrient status and are considered to be useful indicators for nutrient survey studies. Although the present data are strictly only applicable to the Rhizophora species, these are commonly dominant in many mangrove forests in northern Australia and hence this limitation should not detract from the usefulness of foliar analyses as nutrient status indicators.

Acknowledgements. We wish to thank P. Sammarco and W. T. Williams for helpful suggestions concerning the data analysis.

\section{LITERATURE CITED}

Allen, S. E., Grimshaw, H. M., Parkinson, J. A., Quarmby, C. (1974). Chemical analysis of ecological materials. Wiley, New York

Beadle, N. C. W. (1953). The edaphic factor in plant ecology with a special note on soil phosphates. Ecology 34: $426-428$

Boto, K. G., Wellington, J. T. (in press). Soil characteristics and nutrient status in a northern Australian mangrove forest. Estuaries 7 (2)

Bunt, J.S. (1982). Studies of mangrove litter fall in tropical Australia. In: Clough, B. F. (ed.) Structure, function and 
management of mangrove ecosystems in Australia. A.N.U. Press, Canberra, p. 239-257

Bunt, J. S., Boto, K. G., Boto, G. (1979). A survey method for estimating potential levels of mangrove forest primary production. Mar Biol. 52: 123-128

Buresh, R. J., De Laune, R. D., Patrick, W. H. Jr. (1980). Nitrogen and phosphorus utilization by Spartina alterniflora in a Louisiana gulf coast marsh. Estuaries 3: 111-121

Christensen, B. (1978). Biomass and primary production of Rhizophora apiculata B1 in a mangrove in southern Thailand. Aquat. Bot 4: 43-52

Clough, B. F., Boto, K. G., Attiwill, P. M. (in press). Mangroves and sewage - a re-evaluation. In: Teas, G. H. (ed.) Proceedings of the 2nd International Symposium on Biology and Management of Mangroves, Papua New Guinea. W. Junk Publ., The Hague

Duke, N. C. (1981). Data on mangrove litter fall. Aust. Inst. Mar. Sci. (AIMS), Townsville, Data Rep. No. 5

Duke, N. C., Bunt, J. S., Williams, W T. (1981). Mangrove litter fall in north-east Australia. I. Annual totals by component in selected species. Aust. J. Bot. 29: 547-553

Duke, N. C., Bunt, J. S., Williams, W. T. (in press). Floral and vegetative phenology in mangroves of north-eastern Australia. Aust. J. Bot.

Hesse, P. R. (1961). Some differences between the soils of Rhizophora and Avicennia mangrove swamps in Sierra Leone. Plant and Soil 14: 335-346

Kira, T., Ogawa, H., Yoda, K., Ogina, K. (1967). Comparative ecological studies on three main types of forest vegetation in Thailand IV. Dry matter production, with special refer- ence to the Khao Chong rainforest. Nat. Life S. E. Asia 5 $149-174$

Linthurst, R. A., Seneca, E. D. (1981). Aeration, nitrogen and salinity as determinants of Spartina alterniflora Loisel growth response. Estuaries 4: 53-63

Mendelssohn, I. A. (1979). Nitrogen metabolism in the height forms of Spartina alterniflora in North Carolina. Estuaries 2: $106-118$

Onuf, C. P., Teal, J. M., Valiela, I. (1977). Interaction of nutrients, plant growth and herbivory in a mangrove ecosystem. Ecology 58: 514-526

Potts, M. (1979). Nitrogen fixation (acetylene reduction) associated with communities of heterocystous and nonheterocystous blue-green algae in mangrove forests of Sinai. Oecologia (Berl.) 39: 359-374

Rodin, L. E., Basilevic, N. I. (1968). World distribution of plant biomass. In: Eckardt, F. E. (ed.) Functioning of terrestrial ecosystems at the primary production level. Proc. Copenhagen Symp., UNESCO, Paris, France, p. 45-52

Sokal, R. R., Rohlf, F. J. (1969). Biometry, The principles and practice of statistics in biological research. Freeman, San Francisco

Spain, A. V., Holt, J. A. (1980). The elemental status of the foliage and branchwood of seven mangrove species from nothern Queensland. Div. Soils Divisional Report No. 49. CSIRO, Australia

Wolanski, E., Jones, M., Bunt, J. S. (1980). Hydrodynamics of a tidal creek-mangrove swamp system. Aust. J. mar. Freshwat. Res. 31: 431-450 